\title{
Proper Sterile Gloving Technique for Non-Operating Room Sterile Procedures: A Step-by-Step Guide
}

\author{
Omar Viswanath, MD, Musa Aner, MD \\ Harvard Medical School, Department of Anesthesiology, Critical Care, and Pain Medicine, Beth Israel Deaconess Medical Center, Boston, MA
}

\section{TO THE EDITOR}

During the first week of the academic year as I began my fellowship, one of our attending physicians gave us a valuable demonstrative lecture on the proper way to put on sterile gloves. Throughout medical school and residency, I had attended multiple lectures and completed countless mandatory infection control learning modules on the same topic. However, no one had ever physically demonstrated how to properly put on sterile gloves, and I realized that although I had done it hundreds of times, I was performing a few of the steps incorrectly.

To reduce the likelihood of infection, proper sterility is of utmost importance when performing invasive procedures in patients undergoing interventional procedures. Sterile technique applies to many interventions-placing arterial and central lines, obtaining blood cultures, placing urine catheters, and all procedures involving the neuroaxis. Sterility starts with proper gloving technique.

The majority of interventional and noninterventional training programs require trainees to perform a minimum number of these sterile procedures to satisfy graduation requirements. Although trainees attend lectures and complete computer learning modules on this topic, the majority of the programs do not have a formal didactic and demonstration of the important technique of sterile gloving. Many trainees may be gloving improperly and unknowingly putting their patients at risk.
A search of the medical literature revealed a paucity of publications focused on teaching proper sterile gloving to residents, the impact of proper technique, or the relationship between improper technique and subsequent infection rates. Khouli et al attempted to determine the optimal method to teach medical residents correct sterile techniques, including proper sterile gloving, in an effort to reduce catheterrelated bloodstream infections (CRBSI). ${ }^{1}$ They found that compared to the traditional apprenticeship model (residency training), both simulation-based and video training groups had higher median scores in sterility technique that resulted in significantly lower CRBSI.

The World Health Organization "Glove Use Informational Leaflet" includes illustrations and written instructions for donning and removing nonsterile examination gloves. ${ }^{2}$ Some hospital websites have illustrations and written information for patients and their families who will need to use sterile gloves after their discharge..$^{3,4}$

Given the minimal amount of literature focused on proper sterile gloving techniques, we have produced a guide that provides step-by-step photographs with brief instructions for each step. This guide taps into the visual aspect of learning, and the brevity of the instructions aids in learning. The guide demonstrates proper gloving technique from opening and unwrapping the outer covering through to sterile application of the gloves to both hands. 


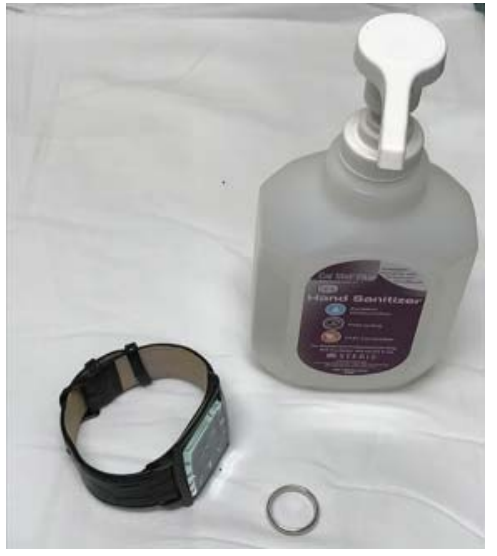

Step 1. Remove unnecessary objects. Remove all jewelry, watches, and rings prior to hand washing. ${ }^{5-6}$

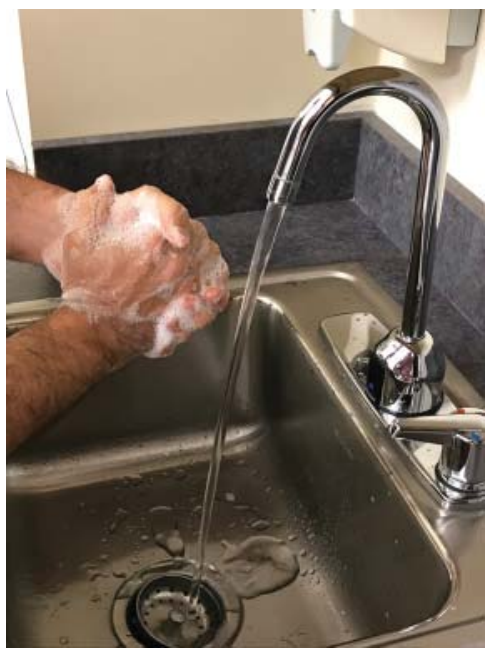

Step 2. Wash hands. Thoroughly wash hands for at least 15 seconds after applying soap generously to both hands. The amount of time is less important than making sure all areas of the hands are cleaned. (Note: Soap and water remove bacteria but are not effective at killing organisms. $)^{5,7-10}$
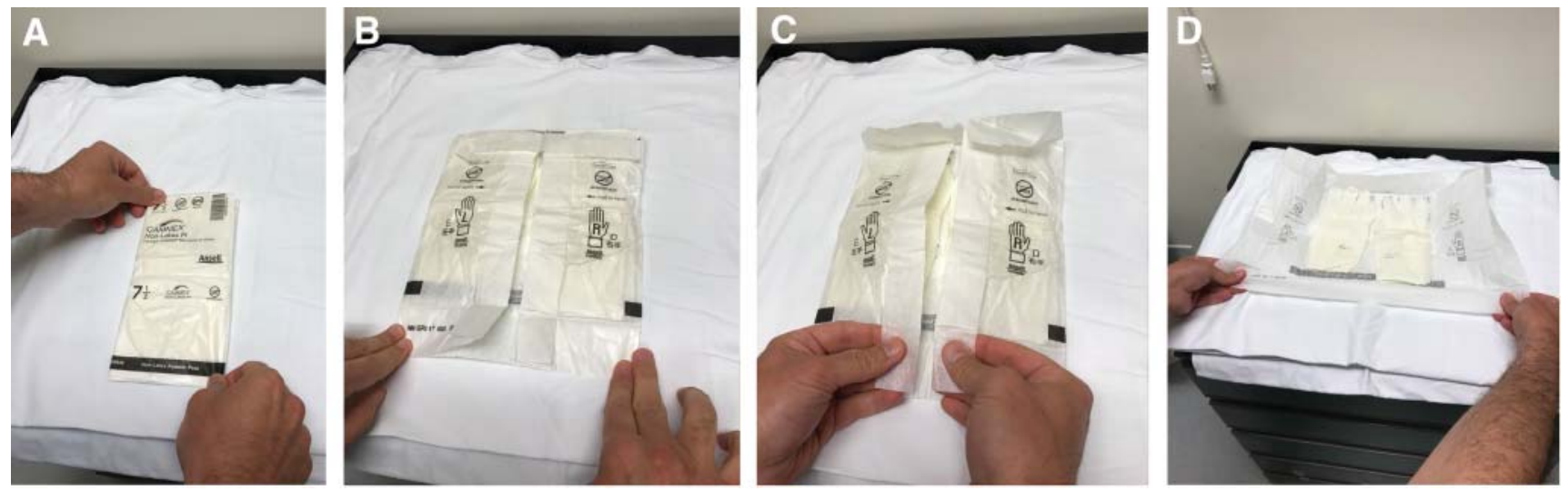

Step 5. Open the inside sterile glove wrapper. Open the inside sterile glove wrapper (5A and 5B) without touching the area of the packaging the gloves contact (5C and 5D). hand sanitizer to both hands for 60 seconds. (Note: Solutions containing an alcohol component are superior. $)^{8,11}$

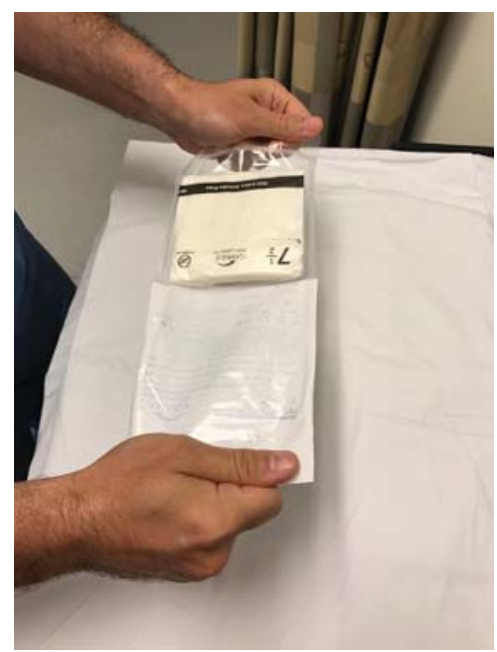

Step 4. Remove sterile gloves from the outer packaging. Remove sterile gloves from the outer packaging in a deliberate and efficient manner as demonstrated in the photograph. ${ }^{12-13}$ 


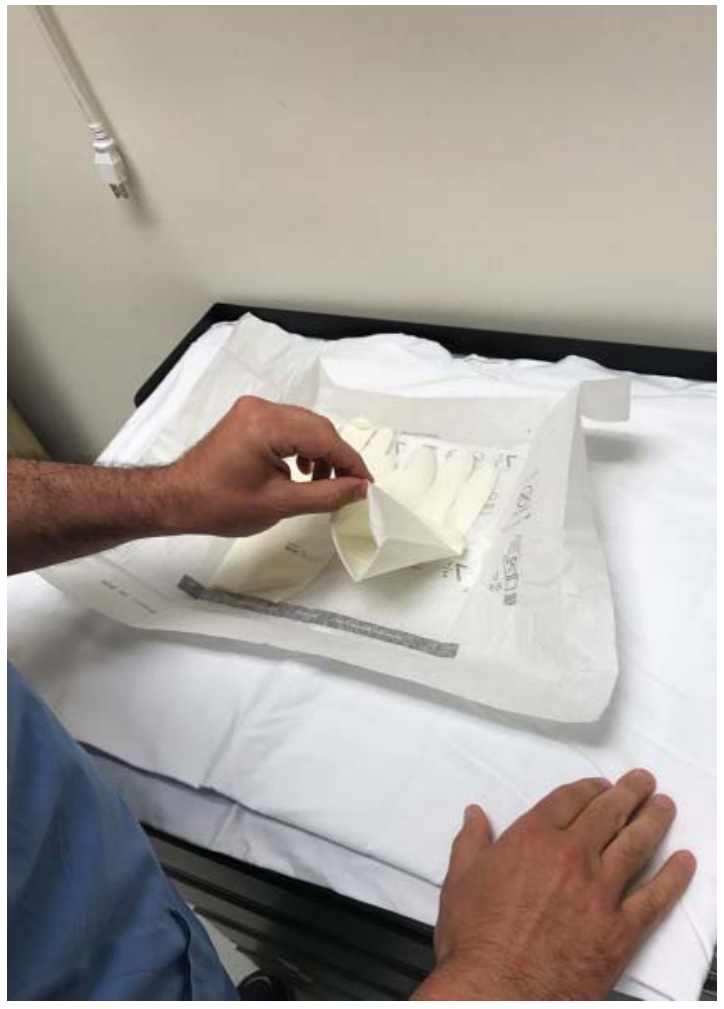

Step 6. Pick up the first glove. Pick up the first glove (right glove shown in the photograph) by the sleeve with the opposite hand (left hand shown in the photograph) only touching the inner surface.
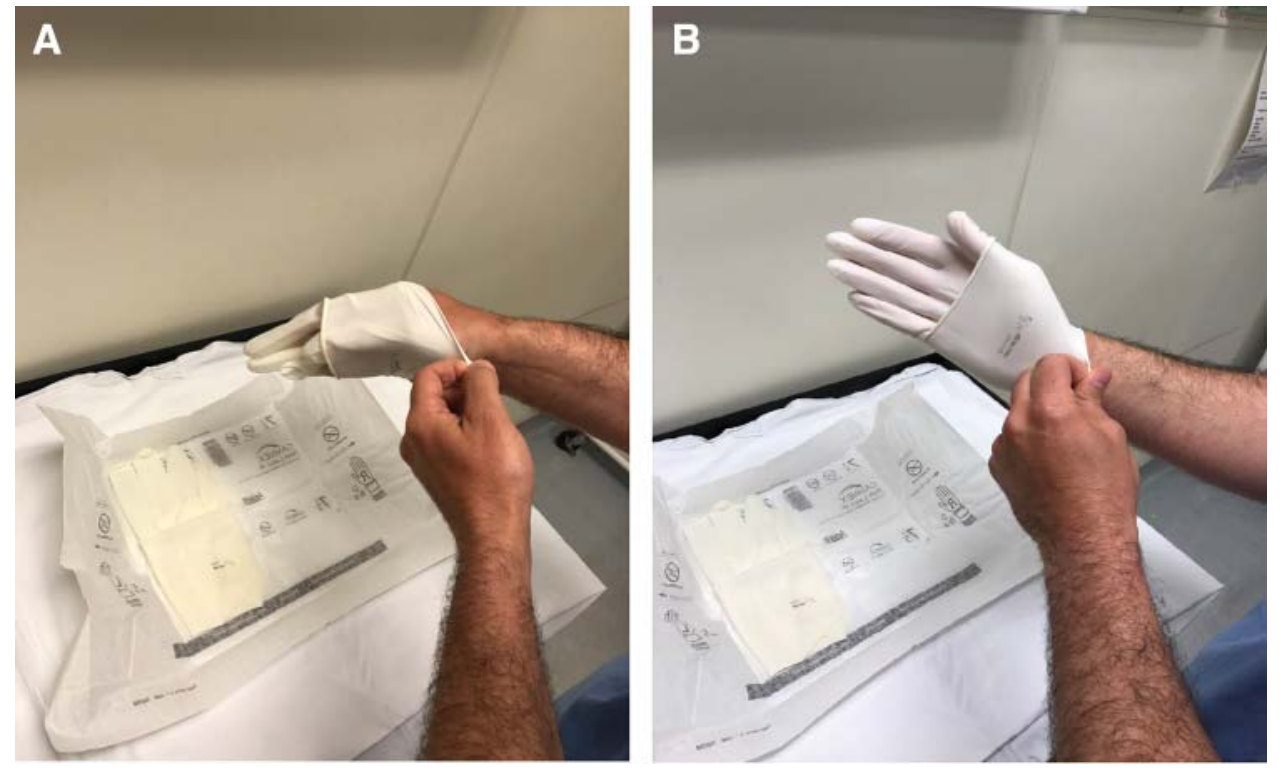

Step 7. Put on the first glove. Insert the hand into the glove (7A) while pulling across with the other hand and continuing to touch only the inner surface until the fingers are in place inside the glove (7B). 

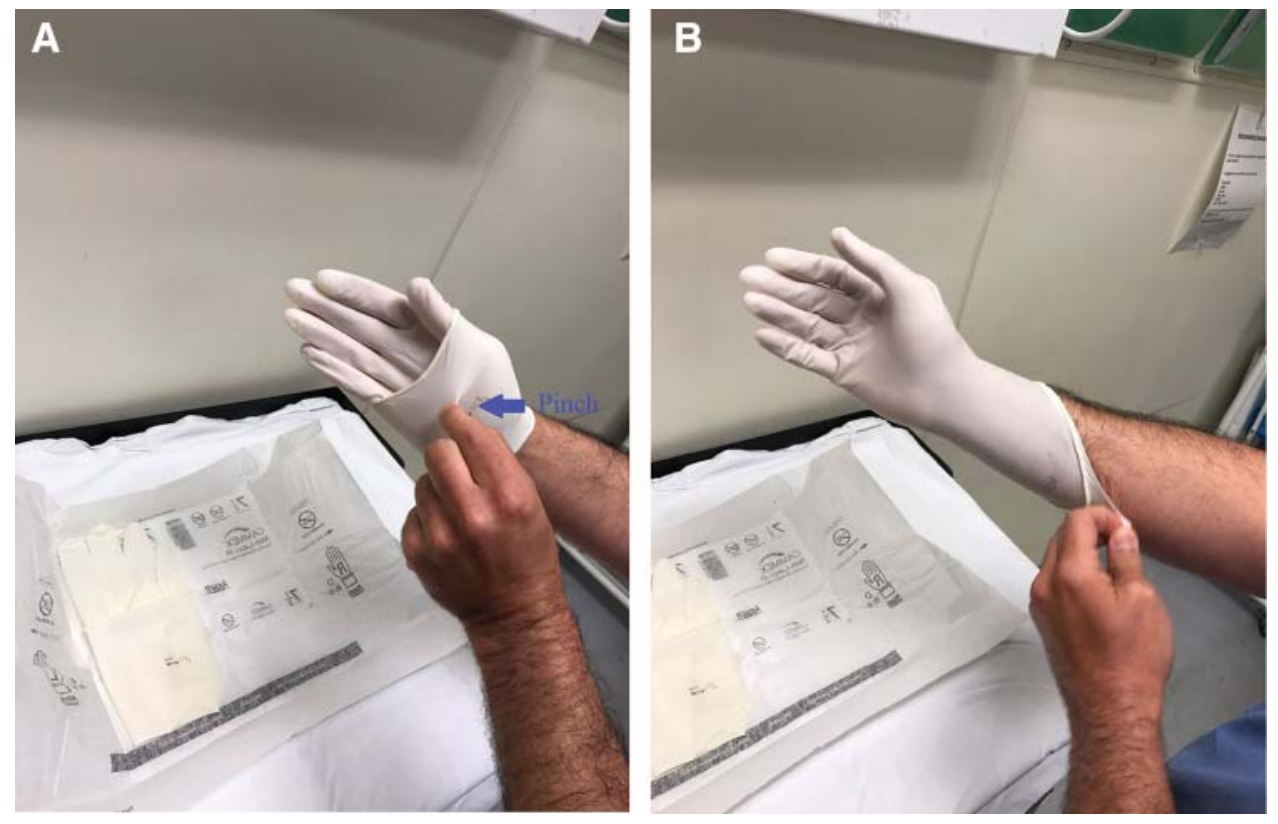

Step 8. Complete placement of the first glove. Using the opposite hand, pinch the palmar surface of the sleeve $(8 \mathrm{~A})$ and then pull back across the length of the arm until the glove is fully extended (8B).
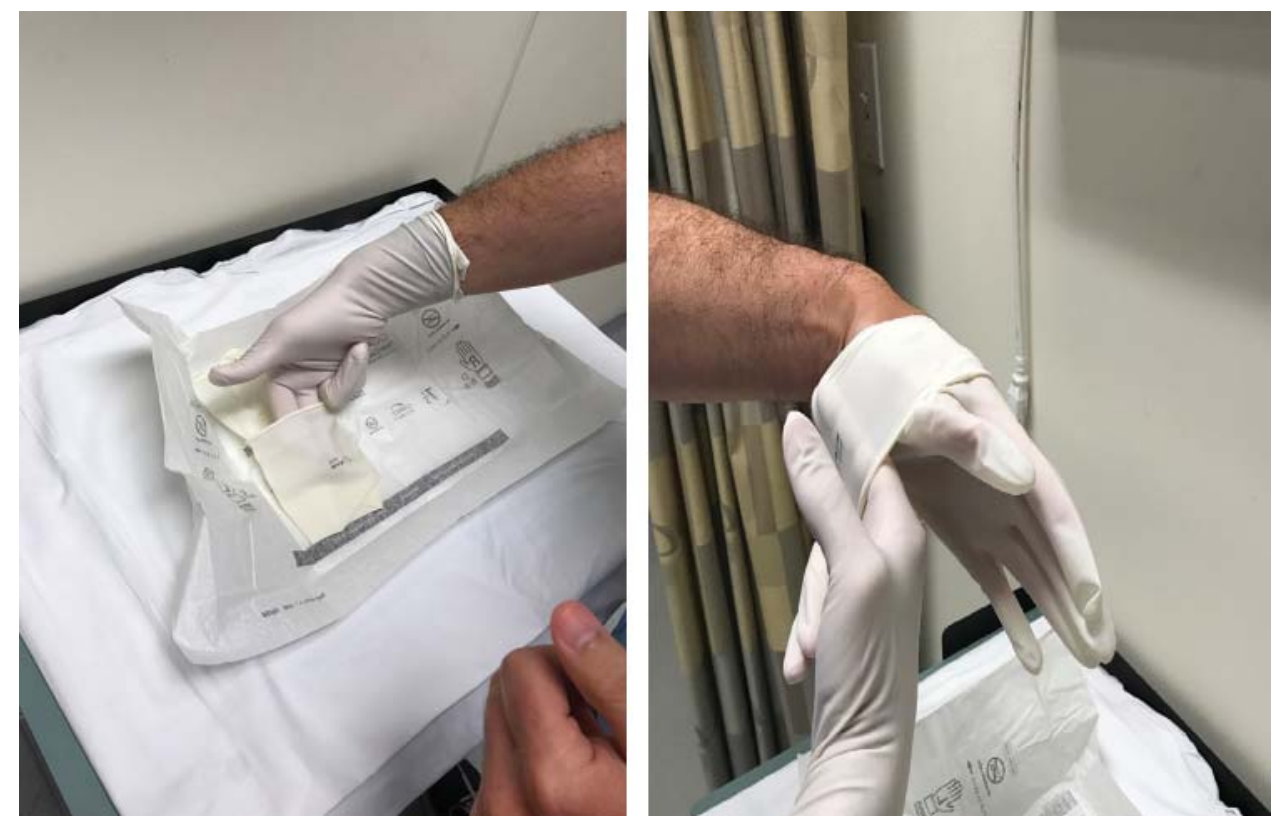

Step 9. Prepare to glove the remaining hand. After properly gloving the first hand, use the second and third digits (or the second through fifth digits) of the already gloved hand (left image) to lift the glove and facilitate placement of the ungloved hand into the remaining glove (right image). 


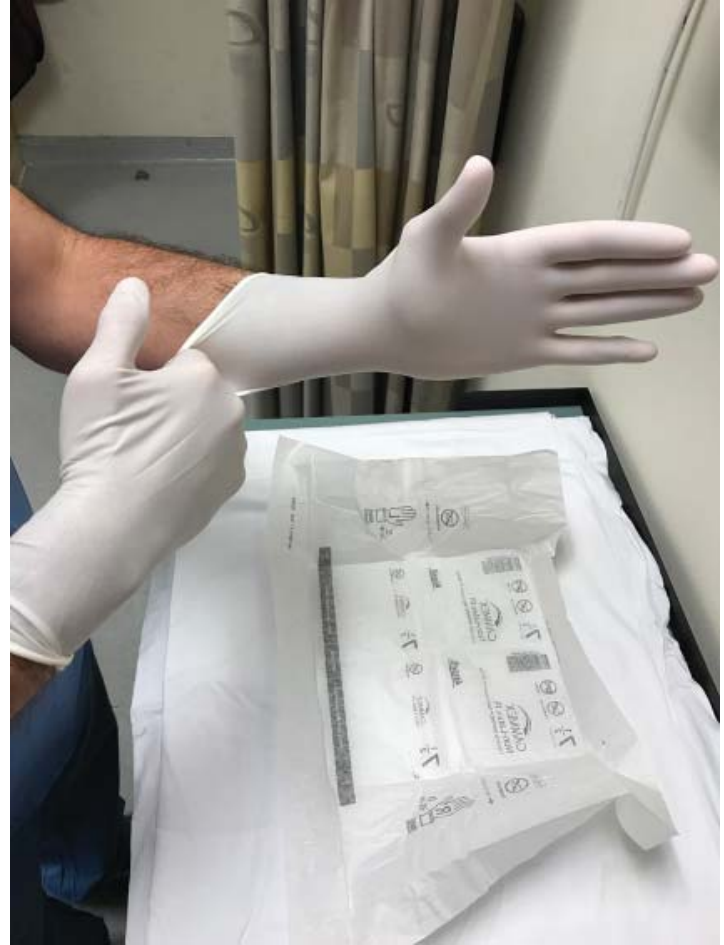

Step 10. Finish gloving the remaining hand. With the same second and third digits (or the second through fifth digits), pull the sleeve across the forearm until the glove is in place.

\section{REFERENCES}

1. Khouli H, Jahnes K, Shapiro J, et al. Performance of medical residents in sterile techniques during central vein catheterization: randomized trial of efficacy of simulationbased training. CHEST. 2011 Jan;139(1):80-87. doi: 10.1378/ chest.10-0979.

2. World Health Organization. Glove use information leaflet. http:/ /www.who.int/gpsc/5may/Glove_Use_Information_Leaflet.pdf. Revised August 2009. Accessed February 1, 2018.

3. St. Jude Children's Research Hospital. How to put on sterile gloves. https://www.stjude.org/treatment/patient-resources /caregiver-resources/patient-family-education-sheets /tracheostomy-care/how-to-put-on-sterile-gloves.html. Published 2018. Accessed February 1, 2018.

4. St. Luke's. Discharge instructions: using sterile glove technique. https://www.saintlukeskc.org/health-library/discharge -instructions-using-sterile-glove-technique. Published January 2018. Accessed February 1, 2018.

5. Hebl JR. The importance and implications of aseptic techniques during regional anesthesia. Reg Anesth Pain Med. 2006 JulAug;31(4):311-323.

6. Salisbury DM, Hutfilz P, Treen LM, Bollin GE, Gautam S. The effect of rings on microbial load of health care workers' hands. Am J Infect Control. 1997 Feb;25(1):24-27.

7. Reybrouck G. Role of the hands in the spread of nosocomial infections. 1. J Hosp Infect. 1983 Jun;4(2):103-110.

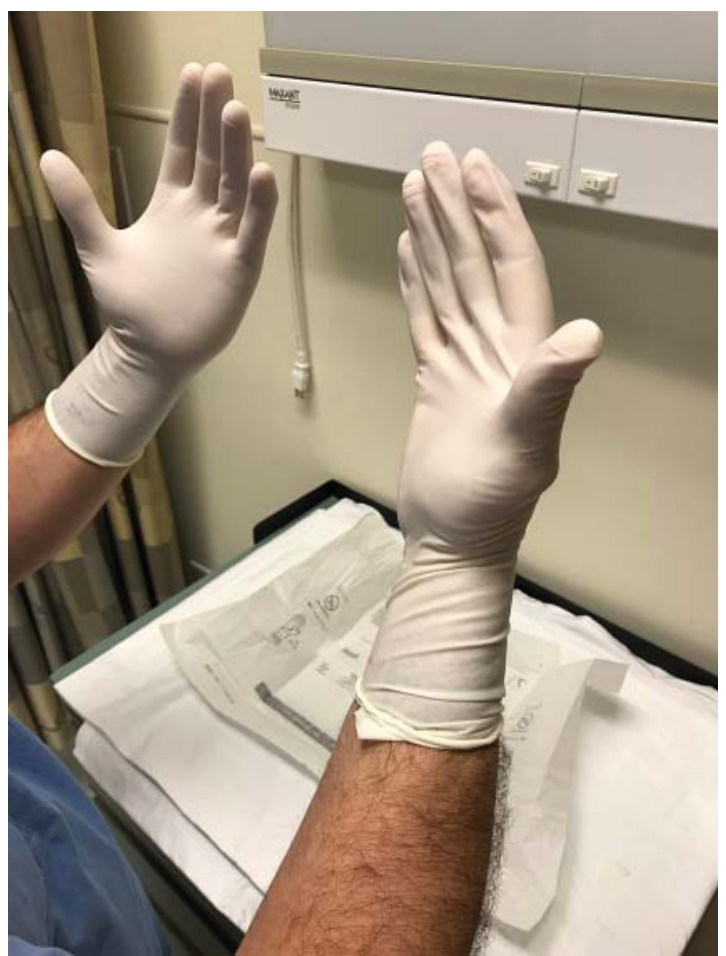

Step 11. Proper sterile gloving is completed. The provider is now ready to perform the planned sterile procedure.

8. Boyce JM, Pittet D; Healthcare Infection Control Practices Advisory Committee. Society for Healthcare Epidemiology of America. Association for Professionals in Infection Control. Infectious Diseases Society of America. Hand Hygiene Task Force. Guideline for hand hygiene in health-care settings: recommendations of the Healthcare Infection Control Practices Advisory Committee and the HICPAC/SHEA/APIC/IDSA Hand Hygiene Task Force. Infect Control Hosp Epidemiol. 2002 Dec;23 (12 Suppl):S3-S40.

9. Handwashing Liaison Group. Hand washing: a modest measure-with big effects. BMJ. 1999 Mar 13;318(7185):686.

10. Daniels IR, Rees BI. Handwashing: simple, but effective. Ann $R$ Coll Surg Engl. 1999 Mar;81(2):117-118.

11. Rotter ML, Hirschl AM, Koller W. Effect of chlorhexidinecontaining detergent, non-medicated soap or isopropanol and the influence of neutralizer on bacterial pathogenicity. $J$ Hosp Infect. 1988 Apr;11(3):220-225.

12. Saloojee $H$, Steenhoff $A$. The health professional's role in preventing nosocomial infections. Postgrad Med J. 2001 Jan;77 (903):16-19.

13. Olsen RJ, Lynch P, Coyle MB, Cummings J, Bokete T, Stamm WE. Examination gloves as barriers to hand contamination in clinical practice. JAMA. 1993 Jul 21;270(3):350-353. 